\title{
O SUJEITO ANÍMICO E O SUJEITO ESPIRITUAL EM IDEIAS II
}

\author{
The psychic subject and the spiritual subject in Ideas II \\ El sujeto anímico y el sujeto espiritual en Ideias II
}

Nathalie Barbosa de la Cadena

\begin{abstract}
Resumo: Neste artigo pretendo evidenciar como a relação entre sujeito anímico e sujeito espiritual é fundamental para a compreensão da intersubjetividade e do mundo da vida (Lebenswelt). Em Ideias II, Husserl explica como, a partir do eu, sujeito e objeto são constituídos no mundo: natureza, alma e espírito. Estes três estratos do sendo são conhecidos a partir da atitude teorética e da atitude espiritual e, no processo, se dá a explicitação do eu. Numa atitude teorética, temos constituição da natureza, para o que o corpo (Körper/Leib) é fundamental. Em seguida, a constituição de objetos de natureza anímica, humana ou animal, incluindo a autopercepção. Assumindo a atitude espiritual, o outro é percebido (Urpräsenz), inicialmente, como corpo junto às coisas e, ao lado desta percepção, há uma apercepção (Appräsenz) dos horizontes co-dados. Há uma identidade entre o corpo alheio e o meu, é o momento da empatia (Einfühlung). O mundo constituído a partir de uma atitude naturalista ou teórica é uma redução do mundo circundante (Umwelt), mas o mundo cotidiano da atitude personalista ou espiritual lhe antecede, o mundo vital (Lebenswelt). É, portanto, através da atitude personalista ou espiritual, que se constitui uma comunidade de sujeitos espirituais.
\end{abstract}

Palavras-chave: Husserl; Alma; Espírito; Intersubjetividade; Mundo da vida.

Abstract: In this article I intend to highlight how the relationship between psychic subject and spiritual subject is fundamental for the understanding of intersubjectivity and the life world (Lebenswelt). In Ideas II, Husserl explains how, from the self, subject and object are constituted in the world: nature, soul and spirit. These three strata of the being are known from the theoretical attitude and the spiritual attitude and, in the process, the self is explicit. In a theoretical attitude we have nature's constitution, for which the body (Körper / Leib) is fundamental. Then the constitution of objects of animic nature, human or animal, including self-perception. Assuming the spiritual attitude, the other is perceived (Urpräsenz) initially as a body together with things, and beside this perception there is an apprehension (Appräsenz) of co-given horizons. There is an identity between the body of others and mine, it is the moment of empathy (Einfühlung). The world constituted from a naturalistic or theoretical attitude is a reduction of the surrounding world (Umwelt), but the everyday world of the personalistic or spiritual attitude precedes it, the life-world (Lebenswelt). It is therefore through the personalistic or spiritual attitude that a community of spiritual subjects is constituted.

Keywords: Husserl; Soul; Spirit; Intersubjectivity; Life-world.

Resumen: En este artículo pretendo destacar cómo la relación entre el sujeto anímico y el sujeto espiritual es fundamental para la comprensión de la intersubjetividad y el mundo de la vida (Lebenswelt). En Ideas II, Husserl explica cómo, desde el yo, el sujeto y el objeto están constituidos en el mundo: naturaleza, alma y espíritu. Estos tres estratos del ser se conocen por la actitud teórica y la actitud espiritual y, en el proceso, el yo es explícito. En una actitud teórica, tenemos la constitución de la naturaleza, para la cual el cuerpo (Körper / Leib) es fundamental. Luego la constitución de objetos de naturaleza anímica, humana o animal, incluida la auto percepción. Asumiendo la actitud espiritual, el otro se percibe (Urpräsenz) inicialmente como un cuerpo junto con las cosas, y además de esta percepción hay una apercepción (Appräsenz) de los horizontes compartidos. Existe una identidad entre el cuerpo de los demás y el mío, es el momento de la empatía (Einfühlung). El mundo constituido por una actitud naturalista o teórica es una reducción del mundo circundante (Umwelt), pero el mundo cotidiano de la actitud personalista o espiritual lo precede, el mundo de la vida (Lebenswelt). Por lo tanto, es a través de la actitud personalista o espiritual que se constituye una comunidad de sujetos espirituales.

Palabras-llave: Husserl; Alma; Espírito; Intersubjetividad; Mundo de la vida.

\section{Introdução}

Neste artigo pretendo evidenciar como a relação entre sujeito anímico e sujeito espiritual é fundamental para a compreensão da intersubjetividade e do mundo da vida (Lebenswelt). Para tanto, antes de abordar o tema específico, será preciso definir as premissas metafísicas, e apresentar uma breve descrição do processo de constituição de objetividades na consciência para, então, expor a relação entre sujeito anímico e espiritual conforme apresentada em Ideias II (HUA IV) ${ }^{1}$. Ideias II está dividida na constituição da natureza material, anímica e espiritual, acompanhada da correspondente mudança de atitude, de teorética para personalista, só então é possível abordar a

\footnotetext{
1 Utilizar-se-á, aqui, a referência usual às obras de Husserl, tal qual se aplica na Filosofia.
} 
intersubjetividade e o mundo da vida. A conclusão aponta para uma linearidade no pensamento de Husserl, ao menos desde as Investigações Lógicas, texto em que estabelece suas premissas metafísicas, até Ideias II, em que aplica o método fenomenológico às três dimensões do sujeito, e extrai daí suas conclusões.

\section{Premissas metafísicas consistentes em Investigacões Lógicas, Ideias I e Ideias II}

As premissas metafísicas assumidas por Husserl estão presentes já nas Investigações Lógicas (HUA XVIII e XIX). Os Prolegômenos (HUA XVIII) são publicados em 1900, e as Investigações (HUA XIX) são publicadas no ano seguinte. Em 1913, ano de publicação de Ideias I (HUA III), Husserl publica uma reedição das Investigações Lógicas, e os Prolegômenos sofrem algumas alterações em sua maioria pouco importantes. Em 1936, Husserl em carta a Cairns (HUA XVIII, p. XLI) afirma que segue considerando as Investigações Lógicas "ainda hoje indispensáveis".

Em 1913, Husserl publica Ideias para uma fenomenologia pura e para uma filosofia fenomenológica, chamada de Ideias I. Ideias II (HUA IV) somente é publicada postumamente, em 1952. No entanto, seu primeiro manuscrito foi terminado em 1912, portanto, contemporâneo a Ideias I. Em 1916, Edith Stein concluiu a primeira redação do manuscrito. Vários pensadores tiveram acesso aos manuscritos de Ideias II, Martin Heidegger, antes da publicação de Ser e tempo, em 1926, Maurice Merleau-Ponty que estudou nos Arquivos Husserl em Louvain, Paul Rickert e Alfred Schütz. ${ }^{2}$

As premissas assumidas por Husserl em Investigações Lógicas e que permanecem coerentemente intactas ao longo de Ideias I e II são a consciência intencional e transcendental e o realismo ontológico.

A primeira premissa de ordem subjetiva é evidente nas Investigações Lógicas, quando Husserl analisa três conceitos de consciência (HUA XIX/1, 378 e s.) e deles extrai a definição fenomenológica. A consciência é intencional (HUA XIX/1, 366) por que é consciência do mundo, está sempre intencionalmente unida ao mundo, é consciência do mundo tal qual vivenciado. A consciência é também transcendental por que a consciência é o agente e o lugar onde o desvelamento do mundo se dá, é lugar de intuição de essências e de constituição de objetualidades. É a unidade real e constante das vivências do eu.

Nas Investigações Lógicas, Husserl deixa claro que a redução ao fenomenológico torna

2 Informações retiradas dos Prefácios de Ideias II, edições em espanhol (México: Fondo de Cultura Económica, 2005) e inglês (London: Kluwer Academic Publishers, first printing, 1989). evidente a unidade da "corrente de consciência" (HUA XIX/1, 369), é dizer, o eu fenomenológico é ontologicamente anterior ao eu empírico, ou ainda, o eu fenomenológico constitui intencionalmente o eu empírico. O "Ser eu não significa ser objecto, mas perante todo e qualquer objecto, ser aquele para quem qualquer coisa é objecto." (HUA XIX/1, 373) Cito:

Para clarificar a situação, não posso encontrar aqui nenhum outro caminho do que submeter a uma análise fenomenológica o eu empírico e a sua relação empírica com os objectos; então, daí resultará necessariamente a concepção que defendemos acima. Eliminámos o eu-corpo, que aparece como uma coisa física tal como qualquer outra, e considerámos o eu espiritual, empiricamente a ele ligado, e que aparece como lhe pertencendo. Reduzido ao dado 'fenomenologicamente actual', ele fornece a complexão acima descrita de vivências 'captáveis reflexivamente'. (HUA XIX/1, 374)

Os conceitos de eu empírico ou eu corpo, eu anímico e eu espiritual, entendido como o grau mais elevado da consciência transcendental, aparecem de maneira muito forte e evidente em Ideias II como veremos a seguir.

No mesmo sentido em Ideias I, Husserl afirma "De um lado, portanto, a consciência deve ser o absoluto, no qual se constitui todo e qualquer transcendente e, por conseguinte, enfim, todo o mundo, psicofísico; de outro, a consciência deve ser um evento real subordinado no interior desse mundo" (HUA III, 103). Ainda no mesmo sentido, "O eu, porém, é um idêntico. [...] $O$ eu puro, em contrapartida, parece ser algo necessário por princípio e, enquanto absolutamente idêntico em toda mudança real ou possível dos vividos, ele não pode, em sentido algum, ser tomado por parte ou momento real dos próprios vividos."

Também nas Meditações Cartesianas, Husserl mantém sua compreensão acerca da consciência. É intencional, "Assim, em geral, toda e qualquer vivência de consciência é, em si mesma, consciência de isto ou aquilo" (HUA I, 71) e, expressamente declara no $\$ 40$ (HUA I, 115) embora enfatizando uma mudança de atitude. É transcendental, "Todas as diferenciações que eu faço entre experiência autêntica e enganadora e, dentro dela, entre ser e aparência, decorrem na minha própria esfera de consciência [...] Toda e qualquer fundamentação, toda justificação da verdade e do ser decorrem, de ponta a ponta, em mim, e sua resultante final é um carácter no cogitatum do meu cogito." É dizer, o lugar de conhecimento, evidenciação e constituição do mundo é a consciência.

$\mathrm{O}$ eu é esta consciência intencional e transcendental voltada para o mundo, mas ao 
mesmo tempo a constante que mantém a unidade diante de todas as vivências, o lugar de intuição de essências e constituição de objetualidades. Este é o campo de investigação da fenomenologia, identificar a essencial estrutural desta relação intencional, que abrange ambos, consciência e mundo como vivenciados.

A segunda premissa de ordem objetiva é o realismo ontológico (NIINILUOTO, 2004, p.1), isto é, a assunção de que o mundo ${ }^{3}$ é uma objetividade independente da subjetividade. Ainda assim, cito aqui algumas passagens de Prolegômenos e Investigações Lógicas que sustentam essa premissa. Nesta Husserl trata da unidade da ciência baseada tanto na unidade de explicação como na unidade da coisa:

Há, porém, em segundo lugar, pontos de vista extraordinários para a coordenação de verdades numa ciência, e ao mais óbvio chamamos a unidade da coisa num sentido mais literal. Ligam-se $<237>$ por seu intermédio todas as verdades que quanto ao seu conteúdo se referem a uma e à mesma objectividade individual, ou a um e o mesmo gênero empírico. Este é o caso das ciências concretas ou, para nos servirmos de um termo de v. Kries, ontológicas, como a geografia, história, astronomia, história natural, anatomia e etc. (HUA XVIII, 237).

Também em Ideias $I$ há algumas passagens (HUA III, 11, 17, 49, 70, 74, 84, 86-87, 98-103), cito apenas uma quando Husserl trata do mundo natural como correlato da consciência:

Isso vale para qualquer espécie imaginável de transcendência que deva poder ser tratada como efetividade ou possibilidade. Jamais um objeto existente em si é tal que não diga nada respeito à consciência e o "eu” da consciência. A coisa é coisa do mundo circundante, mesmo a coisa não-vista, realmente possível, não experimentada, mas experimentável, ou melhor talvez experimentável. (HUA III, 88-89)

Também nas Meditações Cartesianas (HUA I), publicadas em 1931 após as Conferências de Paris de 1929, Husserl reconhece que a evidência do mundo não é apodítica (HUA I, 57/58). No entanto, isto não implica em negar a existência do mundo como independente da subjetividade, mas na tomada de 3 Niiniluoto em Critical Scientific Realism (2004) busca estabelecer diferenças entre o realismo e o idealismo a partir das seguintes perguntas: "Ontológico: O que são entidades reais? Há um mundo independente da mente?; Semântica: A verdade é uma relação objetiva entre linguagem-mundo?; Epistemológico: $\mathrm{O}$ conhecimento sobre o mundo é possível?; Axiológica: A verdade é um propósito da investigação?; Metodológica: Quais são os melhores métodos para perseguir o conhecimento?; Ética:Os valores morais existem na realidade?" [Tradução própria] Feita esta distinção, a pergunta sobre realismo e idealismo ontológica é apresentada à Husserl. No texto Husserlian realism and transcendental idealism (Cadena, 2017) é apresentada uma série de citações e comentadores que sustentam o realismo ontológico de Husserl. uma atitude filosófica crítica, a epoché (HUA I, 60). E assim assume a mesma premissa: "do mesmo que o eu reduzido não é um qualquer pedaço do mundo, também, inversamente, o mundo e qualquer objecto mundano não são um pedaço do meu eu, algo que se possa encontrar realmente na minha vida de consciência como uma parte real [Reell], como um complexo de dados de sensação ou de actos." (HUA I, 65) E mais adiante insiste:

(...) em mim, no quadro da minha vida de consciência transcendentalmente reduzida, tenho experiência do mundo, incluindo os outros, e, segundo, o sentido da experiência, não como formação sintética minha, privada, por assim dizer, mas antes como um mundo que me é alheio, como um mundo intersubjectivo, como sendo para qualquer um, como um mundo acessível para qualquer um nos seus objectos. (HUA I, 123)

Assim, estas realidades ainda não experimentadas podem ser trazidas à condição de dado como parte de um horizonte indeterminado, mas determinável, co-dado, pois seu preenchimento é definido por seu tipo eidético a priori.

Considerando estas premissas, há uma linearidade no pensamento de Husserl não apenas devido a consistente manutenção das premissas metafísicas, mas também devido às ênfases dadas em suas obras que revelam as etapas de apresentação da fenomenologia. Em Investigações Lógicas $^{4}$, Husserl propõe a agenda fenomenológica, apresenta as condições do conhecimento com destaque para a linguagem e enfatiza os atos de consciência, a dimensão noética; em Ideias $I^{5}$, apresenta o método

$4 \quad$ Neste sentido, Pedro Alves (2007) na 'Apresentação da tradução portuguesa' de Investigações Lógicas, segundo volume, parte I, esclarece "E, no entanto, as Investigações lógicas eram apenas uma obra de preparação, mesmo no quando do seu objectivo explícito: a fundamentação da Lógica. A Doutrina da Ciência, que exporia os tipos puros da consciência de objecto, segundo as suas articulações essenciais, no quadro de uma ontologia formal, é um desiderato ainda longínquo nestas Investigações. Estas confinam-se tarefas preliminares: o isolamento da unidade da significação a partir do ato expressivo, entendendo a sua idealidade como "acto em espécie" (primeira investigação); uma análise fenomenológica da consciência do geral, contra as incorreções nominalistas (segunda investigação); uma mereologia formal, definindo os conceitos de objecto dependente e independente e as relações de fundação (terceira investigação); uma gramática pura lógica, mostrando que coisa é o significar, e como as estruturas da formação e derivação de sentido são uma ossatura que as línguas naturais revestem segundo as suas particularidades históricas e empíricas (quarta investigação); uma teoria dos ingredientes constitutivos da consciência de objecto, em torno dos conceitos de matéria intencional e de qualidade de acto (quina investigação); finalmente, uma penetração na relação dos actos intencionais com a intuição correspondente, surpreendendo numa conexão o fenómeno do conhecimento (sexta investigação)." 5 Em Ideias I, na Parte I (HUA III, 1-48), Husserl retoma a distinção entre fato e essência e críticas aos naturalistas, já apresentadas nas Investigações. Na Parte II (HUA III, 48-119), elabora de maneira mais precisa a primeira etapa do método fenomenológico, a tomada da atitude de conhecimento distinguindo-a da atitude natural, reafirma a consciência transcendental como local de evidenciação do mundo e apresenta as premissas das reduções fenomenológicas, eidética e transcendental. Na Parte III (HUA III, 120-264), apresenta 
fenomenológico como caminho para evidenciação de essências, a estrutura transcendental que permite a constituição das objetividades e a necessária relação noético-noemática; em Ideias $I I^{6}$, a ênfase está nas objetividades, no mundo, é movida para o outro extremo, para os conteúdos dos atos de consciência, para a dimensão noemática.

\section{Constituicãão de objetividades na consciência em Ideias I}

EmIdeias I, Husserl reconhece que a constituição de objetividades na consciência transcendental é um desafio para a fenomenologia, é o que chama de Die funktionellen Probleme (HUA III, 176). Considerando a consciência transcendental como o lugar de constituição do mundo transcendente (HUA I, 115-116) pleno de objetividades independentes da subjetividade (HUA III, 11, 17, 49, 70, 74, 84, 86-87, 98-103; HUA I, 57, 65, 95, 123), como é possível sua constituição na consciência?

Primeiro é preciso entender que, para Husserl, constituir é desvelar. Constituir não pode ser confundido com a atitude kantiana de legislar sobre o objeto. O sujeito husserliano está em epoché, com seu juízo suspenso, conhecimentos e categorias entre parênteses. Portanto, não impõe nada à vivência, ao dado, simplesmente intui sua essência e, ainda em estado de epoché, empreende seu desvelamento. Em "Konstitution der Bewußtfeinsgegenftändlichkeiten” (HUA III, 176), Husserl escreve "É preciso, pois, investigar, na universalidade mais abrangente, como unidades objetivas de cada região e categoria se "constituem para a consciência". [...] É preciso estudar sistematicamente e tornar evidente, em universalidade eidética, todas as espécies fundamentais de consciência possível e as alterações que delas fazem essencialmente parte, as fusões, as sínteses" (HUA III, 177).

Constituir também pode ser entendido como doar sentido, e doar sentido não pode ser confundido com criação de objetividades. Coerentemente com o sentido anterior, a doação de sentido não é, portanto, arbitrária, mas vinculada à essência.

pela primeira vez a versão mais elaborada do cerne do método fenomenológico incluindo suas condições subjetivas, a estrutura da consciência, e a distinção e co-dependência entre noese e noema e suas estruturas. Na Parte IV (HUA III, 265-323), a ênfase deixa de ser a dimensão noética (subjetiva) e passa a ser a dimensão noemática (objetiva) da vivência, o objeto de seu sentido, sentido doado pela razão no limite da essência. Algo que será desenvolvido em Ideias II. 6 Em Ideias II, a estrutura da obra é bastante linear. Husserl começa com a aplicação do método fenomenológico apresentado em Ideias I. Primeiro, à natureza em geral, aprofundando nos estratos ônticos da coisa e na relação entre a coisa e o corpo. Nesta etapa Husserl reafirma de maneira clara e distinta seu realismo ontológico. Segundo, é introduzida a ideia de eu puro manifesto em sua realidade anímica que tem no corpo seu instrumento de interação com o mundo. Nesta etapa, Husserl reafirma a consciência como intencional e transcendental. No final da segunda parte e na terceira parte, Husserl estabelece o ato de consciência da empatia como ponto de partida para a relação entre eu-outro, a constituição intersubjetiva do eu espiritual e sua primazia sobre o mundo natural.
Por exemplo, cada coisa efetiva da natureza é representada por todos os sentidos e proposições variavelmente preenchidas, dentre os quais ela, enquanto for e continuar sendo determinada de tal ou tal maneira, é o correlato de vividos intencionais possíveis; ela é, portanto, representada pelas multiplicidades de "núcleos plenos" ou, o que aqui significa o mesmo, de todos os possíveis "modos de aparição subjetivos", nos quais ela pode ser constituída noematicamente como algo idêntico. (HUA III, 279)

Os sentidos são doados de modo dirigido, limitados pela região ontológica e pela essência (HUA III, 279), ou nos termos de Prolegômenos, encerrados numa unidade nomológica e na unidade da coisa (HUA XVIII, 236).

Zahavi (2001, p. 8) afirma

Portanto, devemos enfatizar mais uma vez que a explicação da subjetividade constitutiva procede em conexão inseparável com uma exploração fenomenológica do mundo que está diante dela. Essa interdependência é explicitamente enfatizada por Husserl em sua chamada maneira ontológica de redução, onde ele descreve a maneira pela qual a pesquisa fenomenológica constitutiva avança em etapas de dois pólos constantes (e, portanto, mutuamente determinantes). A elucidação de uma determinada região ontológica, que é então designada como pista condutora transcendental, sistematicamente leva de volta à consciência que a constitui fenomenologicamente, de modo que as objetividades em questão se tornam compreensíveis, em seu sentido e ser, como os produtos essencialmente prescritos das estruturas correlativas da vida cognitiva (17/270 [263]; cf. 6/175 [172]).

As duas formas de constituição, desvelamento e doação de sentido, não são procedimentos arbitrários, voluntaristas, fruto da imaginação ou do querer. Ambos são inexoravelmente dirigidos e limitados pelas essências e regiões ontológicas. Na dimensão subjetiva, os atos de consciência são limitados pelo nexo noético-noemático que determina quais atos são apropriados para cada vivência, capazes de capturar e pensar cada objeto. Na dimensão objetiva, o dado apreendido inicialmente de forma inadequada é determinado por sua essência e, para maior clareza, opera-se a variação eidética segundo seus modos prescritos a priori (HUA III, 310-312). É dizer, sua região ontológica circunscreve um grupo fechado de investigação submetido a determinações e relações noemáticas, e sua essência limita as variações possíveis.

Esta é a constituição ainda individual 
na consciência empírica, em Ideias I, Husserl apresenta o nível seguinte, a constituição da coisa intersubjetivamente idêntica.

\section{De uma constituicão isolada a uma constituição intersubjetiva em Ideias II}

Em Ideias II, o procedimento de descrição de essência proposto em Ideias I é aplicado inicialmente à natureza em geral e depois à coisa. Também em Ideias II estão presentes as premissas assumidas e mencionadas anteriormente, a consciência intencional e transcendental, e o realismo ontológico (HUA IV, 58 e 77). Esta última premissa aparece com força e destaque, subjacente a todo argumento. Ao lado do realismo ontológico é possível identificar mais uma premissa, a regularidade da natureza (HUA IV, 58) que se desdobra no princípio da causalidade. Ambos, premissa e princípio, necessários para que qualquer conhecimento seja possível ${ }^{7}$.

\subsection{Corpo}

O corpo é instrumento de constituição do objetivo, pois é através dele que a vivência da natureza, das coisas e dos outros é possível. O corpo intermedia a relação sujeito objeto. Através dos diversos atos de consciência corpóreos, os atos de percepção, a consciência intencional e transcendental é capaz de realizar uma síntese estética (HUA IV, 19-20) e unificar a multiplicidade contínua de intuições sensíveis.

Neste momento, o corpo ainda não é constituído como objeto, mas como condição de constituição do objetivo. As coisas são dadas ao sujeito (através do corpo) como unidade em um nexo espaço-temporalcausal. Em outras palavras, as sensações constituem as notas da coisa, por exemplo, suas cores, e simultaneamente, as circunstâncias, as relações, por exemplo, a causalidade. (HUA IV, 57). O corpo é parte deste nexo, é o referencial para quem o mundo se revela, um sistema de condicionalidade subjetiva entrelaçado com um sistema de causalidade espaçotemporal (HUA IV, 64-65).

Husserl distingue, então, duas dimensões do corpo. Körper (HUA IV, 154) é o corpo enquanto coisa pertencente ao mundo submetido ao nexo espaço-temporal-causal, a face externa do corpo. Leib (HUA IV, 152-153) é o corpo enquanto órgão perceptivo conectado a uma consciência intencional e transcendental, a face interna do corpo. A vivência de um estímulo externo, por exemplo, tátil, é captada através da percepção sensível, do contato físico entre a mão e a superfície, este estímulo sensível causa uma impressão psíquica, anímica. Neste sentido, Husserl distingue Ausdehnung material, uma expansão material do estímulo sensível, e a Ausbreitung anímica, propagação sensorial do estímulo sensível. (HUA IV, 148-149)

7 Para mais detalhes sugiro a leitura de The constitution of objectivities in consciousness in Ideias I and Ideas II (Cadena, 2019).
O corpo é a única realidade que pode ser movida pelo sujeito, é seu centro físico de referência e orientação no mundo. O mundo se apresenta ao sujeito através do corpo, na verdade, o mundo se apresenta ao corpo e o corpo apresenta o mundo à consciência. O corpo não é somente uma coisa, mas um órgão do espírito (HUA IV, 96).

\subsection{Sujeito anímico}

Mesmo diante desta vinculação estreita entre alma e corpo, a dação da alma não se dá através do corpo, mas como unidade do fluxo de vivências, como uma corrente de consciência, algo com uma essência específica e independente do corpo. A alma difere do corpo (i) por estar em permanente alteração, é por essência um fluxo (HUA IV, 133), (ii) por ser uma unidade infragmentável (HUA IV, 134). Nas palavras de Husserl, "Do eu puro ou transcendental distinguimos, seguindo sempre fielmente o intuitivamente dado, o sujeito anímico real ou a alma, o ser psíquico idêntico que, vinculado realmente com ele o respectivo corpo humano ou animal, compõe o ser duplo susbtancialreal homem ou animal [tierisch], animado [animal].” ${ }^{8}$ (HUA IV, 120)

A relação entre corpo e alma nãoé, portanto, uma relação causal, mas uma relação condicional (HUA IV, 132), variável de acordo com as circunstâncias. A alma depende das seguintes circunstâncias: (i) psicofísicas, depende do corpo; (ii) idiopsíquicas, dependente de si mesma e de suas circunstâncias internas; (iii) intersubjetivas.

Ademais, as almas têm níveis, pois diferem qualitativamente de espécie para espécie. Na alma animal, por exemplo, falta o estrato do pensar teórico em sentido estrito, característico dos sujeitos humanos (HUA IV, 134-135).

O eu é o mesmo, sujeito idêntico da função em todos os atos da mesma corrente de consciência, é o centro de irradiação de toda vida da consciência, afecções e ações, a polaridade dos atos (HUA IV, 105). As ações, as emoções, os estados, as qualidades, os atributos, os interesses, as habilidades, as disposições remetem a uma unidade anímica [seelisch $]^{9}$ (HUA IV, 93). Esta constância no fluxo, esta mesmidade em meio às mudanças, é o ponto referencial das vivências, a fonte dos atos de consciência e o lugar da identidade. Na formação do Ego, a dimensão anímica tem, portanto, precedência em relação à corpórea (HUA IV, 94). Abstraindo o corpo, resta a pergunta: de onde emanam estes atos? Qual a fonte dos estados, interesses, habilidades etc.?

A alma recebe através do corpo estímulos sensíveis, e emana atos de consciência perceptivos,

\footnotetext{
$8 \quad$ Tier $=$ animal (substantivo), tierisch $=$ animado (adjetivo). Compreende somente os animais irracionais, as bestas. Animal = animal (substantivo); animal = animado (adjetivo). Compreende a todos os seres animados incluindo as bestas e os seres humanos.

9 Em Ideias II, Husserl usa consistemente o termo Seele = alma (substantivo) e seelischen $=$ anímica (adjetivo). Geist $=$ espírito (substantivo). Husserl não adota o termo psychisch $=$ psíquico (adjetivo).
} 
sensíveis ou corpóreos, e atos de consciência anímicos e emotivos, ambos involuntários e oriundos de uma fonte constante diante do fluxo de vivências, uma corrente de consciência que é sempre a mesma, um sujeito idêntico. Por exemplo, entro em um ambiente a 45 graus, recebo o estímulo térmico, percebo a quentura, sinto calor e sinto desconforto; ou atravesso uma ponte de cordas a 100 metros de altura, recebo o estímulo visual, percebo a altura, sinto medo.

Mesmo diante de tantas vivências com seus respectivos e diversos atos de consciência, é possível perceber a unidade da qual emanam os atos, uma unidade que não se confunde com o fluxo de vivências nem com os atos através dos quais tais vivências são captadas, é a autopercepção (HUA IV, 99 e 106). Posto de outro modo, o ego, ao mesmo tempo que emana os atos de consciência, que percebe, sente, pensa, julga, age, consegue abstratamente se diferenciar e se destacar de tais atos, perceber a si mesmo como fonte no exercício de sua atividade, e assim pode tornar-se objeto para si mesmo (HUA IV, 101). Aliás, vale lembrar, que tal ideia já está presente na $5^{\mathrm{a}}$ Investigação Lógica (HUA XIX/1, 361-365).

$\mathrm{O}$ eu, ao pensar sobre si mesmo, se converte em objeto de um novo ato de consciência, sendo este ato um ato do mesmo eu, e assim o eu pensante capta a si mesmo como eu pensado em seu momento anterior. A Autopercepção capta o eu como unidade na duração. $\mathrm{O}$ eu percebe a si mesmo na vivência, ativo, interagindo, como vida vivida, este é o sujeito anímico.

\subsection{Da atitude naturalista à atitude personalista, do anímico ao espiritual, do individual ao intersubjetivo}

Até aqui Husserl valoriza uma atitude naturalista ou teórica. Nesta atitude, o sujeito pensa de modo científico-natural, busca padrões, regularidades, repete, tenta listar e controlar as variáveis, medir. $\mathrm{O}$ investigador está numa atitude de conhecimento, mas ainda uma atitude científiconatural, não uma atitude fenomenológica. Por isso se esforça para afastar as emoções, valora com juízos lógicos e abstrai os demais valores (HUA IV, 25-26). É uma atitude ativa que não se limita a um conjunto de atos dóxicos (HUA IV, 3-4). A visada pode ser individual ou categorial, ambas realizadas por atos de nível superior (HUA IV, 6).

Nesta atitude, são constituídos os objetos materiais, incluindo os objetos de natureza anímica, os animais e os humanos. Os humanos são dados através do corpo em imediata apreensão, intuição eidética que capta a individualidade espiritual, habilidades, destrezas intelectuais e práticas, seu caráter e mentalidade (HUA IV, 139 in fine). Há ainda um plus, o sujeito humano é apreendido em suas circunstâncias, em seu contexto cósico, em relação de dependência com seu entorno (HUA IV, 140). Em sua atitude natural, teórica, emocional e prática é condicionado por coisas e por si mesmo, condicionamento físico-psíquico e idiopsíquico. No entanto, isto não implica uma determinação, mas apenas uma condição necessária. Por exemplo, para jogar futebol, preciso ter o movimento das pernas preservado (condição fisiopsíquica); para ser uma boa jogadora de futebol, preciso ter talento e disciplina (condição idiopsíquica); mas, mesmo tendo estas duas condições atendidas, não implica que serei uma jogadora de futebol.

\section{Cito Husserl:}

(...) a dependência fisiopsíquica e idiopsíquica está de algum modo acolhida; o que, no entanto, não desempenha um papel propriamente dito em todos os nexos especificamente personalistas nos quais a personalidade manifesta suas propriedades personalistas. O notável nisto é que dizemos que o eu anímico e o personal são em seu subsolo o mesmo [...] (HUA IV 141)

Em outras palavras, a realidade da pessoa consiste em ter propriedades reais como propriedades personalistas/espirituais que possuem relações sob regras com o corpo, com a alma e com o mundo circundante. Por outro lado, a dependência fisiopsíquica e idiopsíquica está contemplada, mas no que diz respeito aos diversos estados de coisas em que a personalidade (ou o espírito) manifesta suas propriedades personalistas (ou espirituais), elas [as dependências fisiopsíquicas e idiopsíquicas] não desempenham um papel determinante, mas apenas condicionante.

Há ainda mais um nível de circunstâncias e dependência ou condicionamento, a relação com outras pessoas, pessoa e comunidade, pessoa e instituições sociais, o Estado, os costumes, o direito, a Igreja etc. (HUA IV, 141). No exemplo acima, temos as condições fisiopsíquicas e idiopsíquicas atendidas, mas mesmo assim é preciso lutar por igualdade de oportunidades para ser jogadora de futebol (condição intersubjetiva).

Este horizonte cósico, incluindo as coisas e os outros, é apercebido como co-dado. O outro é percebido, inicialmente, como corpo dentre as coisas e, ao lado desta percepção, há a apercepção dos horizontes co-dados. O mundo dado a mim é o mesmo mundo dado ao outro, é o mesmo mundo compartilhado. Há a percepção originária (Urpräsenz) e há a percepção correspondente como co-presença (Appräsenz). Capto o seu corpo e simultaneamente suas circunstâncias, capto o alter ego e o horizonte co-presente de significações (HUA IV, 162-163) que nos circunda.

O que inicialmente era captado como coisa, como corpo animado, passa a ser captado como semelhante 
a mim, trata-se de uma apreensão por analogia (HUA IV, 168), um momento da empatia (Einfühlung) (HUA IV, 167). O momento do encontro entre o eu e o outro inicia com o reconhecimento do outro sujeito como organismo animado dotado de movimentos corporais, expressões, gestos, discurso e vontade autônomos. $\mathrm{O}$ outro age de maneira independente, me desafia, frustra minhas expectativas, sou obrigado a me explicar, a sair da minha zona de conforto e interagir. O outro faz parte deste mundo circundante (Umwelt) que me condiciona, o outro me condiciona, pois governa espontaneamente seus movimentos e ações, é vida consciente. É através do ato de consciência da empatia que eu apercebo o mundo interpessoal (HUA IV, 198). Compreendo o meu corpo e o seu corpo, aqui e ali, numa co-presença de horizontes compartilhados. Trata-se de uma comunidade de sujeitos espirituais.

Neste ponto, a atitude faz toda a diferença. Numa atitude naturalista ou teórica, a alma não passa de epifenômeno (HUA IV, 175) e o mundo circundante (Umwelt) é compreendido como o mundo da natureza, o mundo das ciências naturais, o mundo da causalidade. Numa atitude personalista ou espiritual, o eu e o outro são apreendidos como unidades de consciência intencional e transcendental (mônadas superiores) que compartilham horizontes co-dados, compartilham este mundo circundante, e são capazes de desvelar essências e doar sentidos, capazes de atos de julgamento, valoração, comunicação, reivindicação, contestação, adoração e comunhão. Em outras palavras, para compreender esta comunidade de sujeitos espirituais, uma atitude teórica ou naturalista já não é suficiente, é preciso assumir uma nova atitude, uma atitude personalista, ou espiritual, ou prático-valorativa (HUA IV, 183).

\section{Mundo da vida}

O conceito de mundo da vida traz ênfases distintas ao longo das obras de Husserl, mas isto não quer dizer que seja inconsistente. Como citado no início deste artigo, o primeiro manuscrito de Ideas II data de 1912 e, nesta obra, Husserl ainda não usa o termo mundo da vida (Lebenswelt), mas há um predecessor conceitual, mencionado no tópico acima, o mundo circundante (Umwelt), um mundo comum de horizontes co-dados.

No mesmo sentido, nos textos de 1920, mais especificamente em Phänomenologische Psychologie (1925), Husserl toma o mundo da vida como o mundo da experiência (Erfahrungswelt), um mundo circundante comum povoado de objetos, animados e inanimados. Os objetos são experimentados como coisas mentalmente relevantes, dotadas de sentido numa relação eidética material-mental, é dizer, há uma correspondência entre a estrutura da matéria sensorialmente experimentada e a estrutura mental. "Portanto, existe uma analogia entre a maneira como esses objetos são experimentados e a maneira pela qual, ao experimentar um homem, experimentamos uma unidade de corpo e alma." (HUA IX, 111)

Ainda no mesmo sentido, nos seus textos tardios, especialmente Die Krisis der europäischen Wissenshaften und die transzendentale Phänomenologie (1935), Husserl vai desenvolver o conceito de mundo da vida. O mundo da vida é o único mundo efetivo (HUA VI, 49), universal-comum (HUA VI, 128). O mundo da vida é dado à percepção como o único mundo experienciado e experienciável (HUA VI, 49), domínio das evidências originárias (HUA VI, 130), o nosso mundo da vida quotidiano, pré-científico, mundo circundante (HUA VI, 50).

Husserl reconhece que há alguma dificuldade em explicar a objetividade do mundo da vida considerando que a primeira epoché havia suspendido o juízo sobre todas as ciências objetivas, no entanto, afirma:

A dificuldade desaparece, contudo, assim que reflectimos que este mundo da vida, em todas as suas relatividades, tem sua estrutura geral. Esta estrutura geral, a que todo o ente relativo está vinculado, não é ela mesma relativa. Podemos observá-la na sua generalidade, e com o devido cuidado estabelecê-la igualmente acessível de uma vez por todas e para todos. O mundo, como mundo da vida, tem já précientificamente as "mesmas" estruturas que as ciências objectivas, com a sua substrução (que pela tradição dos séculos se tornou numa obviedade) de um mundo existente "em si”, determinado em "verdades em si”, pressupõem como estruturas a priori, e sistematicamente desdobram em ciências a priori, em ciências do logos, normas metódicas universais a que se tem de vincular todo o conhecimento do mundo que é “em si objectivo”. (HUA VI, 142)

Há, portanto, o a priori do mundo da vida e todo a priori objetivo está remetido ao a priori do mundo da vida. O a priori matemático e todo o a priori objetivo é um operação idealizadora do $a$ priori do mundo da vida. (HUA VI, 143). É dizer, há estruturas universais: o a priori universal do mundo da vida que é substrato do a priori universal das ciências objetivas.

É neste contexto que Husserl diz que a lógica inteiramente autônoma como ciência universal $a$ priori fundamental para todas as ciências objectivas é uma ingenuidade (HUA VI, 144), não por que ela seja uma construção humana histórica e arbitrária, mas por que não se pergunta sobre seus próprios fundamentos. Para tanto é preciso a recondução ao a priori universal pré-lógico a partir do qual todo o lógico é possível (HUA VI, 144). Uma ciência do a priori do mundo da vida, a fenomenologia.

O relevante aqui é que, apesar de Husserl deixar bastante clara esta estrutura a priori do 
mundo da vida como condição de validade para todo o conhecimento posterior (HUA VI, 143), reconhece que este a priori do mundo da vida é dado ao sujeito e, somente neste sentido, é relativo ao sujeito. Isto não implica num mundo criado ou dependente da subjetividade e dos processos históricos. Sim, as ciências fazem parte deste mundo da vida e como tal devem também sofrer a epoché, mas há ainda um mundo comum, horizontes co-dados, no qual as essências e as relações entre essências se manifestam. Não é um mundo arbitrário, mas um mundo desvelado intersubjetivamente, e é papel do filósofo recuperar este mundo da vida (Brainard, 2007).

Neste sentido Nenon (2013), explica como a atividade tipicamente espiritual do ego, a atividade espiritual, é importante para a passagem do individual ao intersubjectivo:

(...) o ego não é meramente passivo [...] não somos apenas ativos no sentido de "reagir" passivamente e nem sempre simplesmente seguimos esses impulsos imediatos, mas também podemos responder a eles ativamente em um outro sentido, não apenas em ações no sentido de interações com as coisas no mundo, mas também em nossas próprias respostas a esses impulsos imediatos.

Esta consideração conduz a um outro ponto, nomeadamente o humano, visto que "geistige" é algo que nós, como pessoas, não apenas experimentamos, mas também moldamos e desempenhamos [...]

O mundo geistige não é o mundo natural de realidades teoricamente determinadas, mas sim o mundo prático em que nossa compreensão de predicados de valor e fins é constitutiva de nossa experiência de realidades (e idealidades) que experimentamos lá. A descrição do mundo da vida como aquele que é acima de tudo um mundo prático $[\ldots]$

É neste mundo dado e compartilhado por seres espirituais que através de atos comunicativos (HUA IV, 171) e sociais (HUA IV, 184) é possível vivenciar tradições, religião, política, cultura, esporte, arte etc. O mundo é o mundo cotidiano, mundo vivido (Lebenswelt), mundo governado pela motivação que constitui a sociabilidade, uma comunidade de sentidos doados de maneira compartilhada através de atos comunicativos e atos sociais, mas limitados pelas essências presentes no mundo circundante comum (HUA IV, 191). Cito Husserl:

Como pessoa sou o que sou (e toda outra pessoa é o que é) enquanto sujeito de um mundo circundante. Os conceitos de eu e mundo circundante estão inseparavelmente referidos um ao outro. Assim, a cada pessoa lhe pertence seu mundo circundante, enquanto por sua vez várias pessoas em comunicação umas com as outras tem um mundo circundante comum. (HUA IV, 185).

Não se deve, portanto, interpretar o mundo da vida como "subjective-relative historial world" (Tani, 1986, p. 61). Nada que se assemelhe a um construcionismo social. No nosso exemplo, a jogadora de futebol - penso em Marta Vieira da Silva - primeiro atendeu às condições físico-psíquicas e idiopsíquicas, para posteriormente, ser atendida a condição intersubjetiva, o reconhecimento de seu talento. Este reconhecimento não é uma construção social arbitrária e infundada, mas é baseado nas condições psicofísicas, o corpo de Marta é plenamente funcional; nas condições idiopsíquicas, Marta tomou uma decisão, manteve por convicção, realizou um grande esforço com determinação e persistência; e só então, houve ocasião para a satisfação das condições intersubjetivas, o reconhecimento do seu talento, as ofertas de trabalho e patrocínio, até ser escolhida seis vezes como melhor jogadora de futebol do mundo. Cada uma destas relações é potencializada e limitada por uma estrutura eidética a priori.

O conceito de mundo da vida traz uma constante ao longo das obras de Husserl, (i) primeiro, é o mundo objetivo no sentido de independente da subjetividade, a priori, universal, ordenado segundo uma estrutura eidética; (ii) segundo, é o mundo circundante, comum, compartilhado, de horizontes co-dados, no qual todos os sujeitos vivem e o que todos os sujeitos experienciam; (iii) terceiro, é o mundo condição de possibilidade e de validade de todo o conhecimento produzido; (iv) quarto, é o mundo no qual os sujeitos vivem suas vidas, estabelecem suas relações, constroem sua história, tudo isto antes de produzir qualquer conhecimento objetivo.

\section{Conclusão}

Husserl parte e permanece vinculado ao sujeito, sujeito este em constante relação com a realidade, é dizer, em momento algum abandona, ou sequer tergiversa, sobre suas premissas primeiras, a consciência intencional e transcendental é uma constante para quem o mundo real independente da subjetividade - a priori - se apresenta e, sobre este mundo compartilhado, os sujeitos espirituais, potencializados e limitados por suas essências, doam sentidos, julgam, valoram, estabelecem seus hábitos e vivem sua cultura e sua história.

Portanto, Husserl faz uma trajetória linear e consistente entre Investigações Lógicas, passando por Ideias I até Ideias II. Não só mantém-se firmemente aderido às suas premissas metafísicas, ontológicas e antropológico-filosóficas, como desenvolve o projeto da fenomenologia não apenas como método, mas como possibilidade de compreensão do ser humano, de sua interação com o mundo e com os outros. Husserl parte 
de uma crítica ao psicologismo, propõe a consciência como intencional e transcendental, investiga os atos de consciência e sua estrutura, apresenta o método fenomenológico e sua potencialidade e, finalmente, o aplica desvelando toda a beleza do mundo da vida como uma comunidade de sujeitos espirituais que intuem e descrevem essências, além de doar sentidos de forma comum.

\section{Referências}

Brainard, M. (2007). "For a New World": On the practical impulse of Husserlian theory. Husserl Studies, 23:17-31. Springer Science+Business Media B.V.

Cadena, N. (2019). The constitution of objectivities in consciousness in Ideas I and Ideias II. Revista Filosófica Aurora, Curitiba, v. 31, n. 53, p. 503-5019, maio/ago.

Cadena, N. (2017). Husserlian realism and transcendental idealism. Em Adriano Correia [et al.] (Orgs.), Fenomenologia e hermenêutica (pp. 6475). São Paulo: ANPOF (XVII Encontro).

HUAI.CartesianischeMeditationenundPariserVorträge. Hrsg. und eingeleitet von Stephan Strasser. Nachdruck der 2. verb. Auflage.

Husserl, E. (2010). Meditações Cartesianas. Conferências de Paris. (Pedro M.S. Alves, Trad.) Braga: Tipografia Abreu, Souza \& Braga, Lda.

Husserl, E. (1985). Meditaciones Cartesianas (José Gaos e Migual García-Baró, Trads.) México: Fondo de Cultura Econômica.

HUA III. Ideen zu einer reinen Phänomenologie und phänomenologischen Philosophie. Erstes Buch: Allgemeine Einführung in die reine Phänomenologie.

Husserl, E. (2006). Ideias para uma fenomenologia pura e para uma filosofia fenomenológica. (Márcio Suzuki, Trad.) Aparecida, SP: Idéias \& Letras. (Originalmente publicado em 1913)

Husserl, E. (1983). Ideas pertaining to a pura phenomenology and to a phenomenological philosophy. First book. (F. Kersten, Trad.) The Hague: Kluwer Academic Publishers.

HUA IV. Ideen zu einer reinen Phänomenologie und phänomenologischen Philosophie. Zweites Buch: Phänomenologische Untersuchungen zur Konstitution.

Husserl, E. (2005). Ideas relativas a una fenomenología pura y una filosofía fenomenológica. Libro segundo: Investigaciones fenomenológicas sobre la constitución. (Antonio Zirión, Trad.) México: UNAM, Instituto de Investigaciones Filosóficas, Fondo de Cultura Económica.
HUA XVIII. Logische Untersuchungen. Erster Band: Prolegomena zur reinen Logik.

Husserl, E. (2005). Investigações Lógicas. Primeiro volume: Prolegómenos à Lógica Pura. (Diogo Ferrer, Trad.) Lisboa: Centro de Filosofia da Universidade de Lisboa.

HUA XIX. Logische Untersuchungen. Zweiter Band: Untersuchungen zur Phänomenologie und Theorie der Erkenntnis.

Husserl, E. (2007). Investigações Lógicas. Segundo volume, Parte I: Investigações para a Fenomenologia e a Teoria do Conhecimento. (Pedro M. S. Alves e Carlos Aurélio Morujão, Trad.) Lisboa: Centro de Filosofia da Universidade de Lisboa.

Husserl, E. (2007). Investigações Lógicas. Segundo volume, Parte II: Investigações para a Fenomenologia e a Teoria do Conhecimento (Carlos Aurélio Morujão, Trad.) Lisboa: Centro de Filosofia da Universidade de Lisboa.

Husserl, E. (1976). Investigaciones lógicas (Manuel G. Morente y José Gaos, Trad.) Madrid: Revista de Occidente.

HUA VI. Die Krisis der europäischen Wissenschaften und die transzendentale Phänomenologie.

Husserl, E. (2008). A crise das ciências européias e a fenomenologia transcendental. Uma introdução à filosofia fenomenológica. (Diogo Falcão Ferrer, Trad.) Lisboa: Centro de Filosofia da Universidad de Lisboa.

Nenon, T. (2013). Intersubjectivity, Interculturality, and Realities in Husserl's Research Manuscripts on the Life-World (Hua XXXVII). Em Rasmus Thybo Jensen and Dermot Moran (Orgs.), The Phenomenology of Embodied Subjectivity (pp. 143-163). Switzerland: Springer.

Tani, T. (1986). Life and the Life-world. Husserl Studies 3:57-78. Dordrecht: Martinus Nijhoff Publishers.

Nathalie Barbosa de la Cadena (Orcid: https://orcid. org/0000-0002-4271-1025), Universidade Federal de Juiz de Fora. Email: nathalie.cadena@ufjf.edu.br / nbcadena@gmail.com

Recebido em 25.10.2019

Aceito em 28.01.2021 